\title{
Allgemeines Abkürzungsverzeichnis
}

\section{Abkürzungen der biblischen Bücher in alphabetischer Reihenfolge}

(nach den Loccumer Richtlinien)

\begin{tabular}{ll} 
1 Joh & 1. Johannesbrief \\
1 Kor & 1. Korintherbrief \\
1 Tim & 1. Timotheusbrief \\
2 Kor & 2. Korintherbrief \\
2 Petr & 2. Petrusbrief \\
2 Sam & Das 2. Buch Samuel \\
2 Tim & 2. Timotheusbrief \\
Apg & Apostelgeschichte \\
Dan & Das Buch Daniel \\
Dtn & Deuteronomium \\
Ez & Das Buch Ezechiel \\
Ex & Exodus \\
Gen & Genesis \\
Hebr & Hebräerbrief \\
Hos & Das Buch Hosea \\
Jak & Jakobusbrief \\
Jer & Das Buch Jeremia \\
Jes & Das Buch Jesaja \\
Joel & Das Buch Joel \\
Lk & Lukasevangelium \\
Mk & Markusevangelium \\
Mt & Matthäusevangelium \\
Joh & Johannesevangelium \\
Nah & Das Buch Nahum \\
Num & Numeri \\
Röm & Römerbrief \\
Phil & Philipperbrief \\
Ps & Die Psalmen \\
Sir & Das Buch Jesus Sirach \\
Spr & Das Buch der Sprichwörter \\
\hline
\end{tabular}

Zitate aus dem Alten Testament folgen der Biblia Hebraica Stuttgartensia (BHS), Stuttgart 19671977, online veröffentlicht von der Deutschen Bibelgesellschaft unter: http://www.bibelwissen schaft.de/online-bibeln/biblia-hebraica-stuttgartensia-bhs/informationen-zur-bibelausgabe/ (zuletzt abgerufen am 04. Juli 2021).

Zitate aus dem Neuen Testament folgen dem Novum Testamentum Graece (Nestle-Aland), 28. Auflage, online veröffentlicht von der Deutschen Bibelgesellschaft unter: http://www.bibelwis 
senschaft.de/online-bibeln/novum-testamentum-graece-na-28/informationen-zur-bibelausga be/ (zuletzt abgerufen am 04. Juli 2021).

Die deutschen Übersetzungen basieren auf der sogenannten Menge-Bibel, da diese eine besondere Nähe zu den originalen hebräischen und altgriechischen Texten aufweist. Die elektronische Ausgabe ist dank der Deutschen Bibelgesellschaft online zugänglich unter: http://www.bi belwissenschaft.de/online-bibeln/menge-bibel/informationen-zur-bibelausgabe/ (zuletzt abgerufen am 04. Juli 2021). 


\section{Weitere allgemeine Abkürzungen}

AL Augustinus-Lexikon, Dodaro, R./MAYeR, C./MüLleR, C. (Hg.), Zentrum für AugustinusForschung an der Julius-Maximilians-Universität Würzburg, unter der Verantwortung der Akademie der Wissenschaften und der Literatur in Mainz, Basel $1968 \mathrm{ff}$.

BKV Bibliothek der Kirchenväter, 1. und 2. Aufl., Kempten - München 1869-1938.

CAG Commentaria in Aristotelem Graeca, Berlin 1882-1909.

CCSL Corpus Christianorum. Series Latina, Turnhout $1953 \mathrm{ff}$.

CSEL Corpus Scriptorum Ecclesiasticorum Latinorum, Wien - Prag - Leipzig $1866 \mathrm{ff}$.

CMG Corpus Medicorum Graecorum, hrsg. von der Berlin-Brandenburgischen Akademie der Wissenschaften, Berlin $1927 \mathrm{ff}$.

CSCO Corpus Scriptorum Christianorum Orientalium, Leuven $1903 \mathrm{ff}$.

DK Die Fragmente der Vorsokratiker, Diels, H./Kranz, W. (Hg.), 3 Bde., Berlin $1961^{10}$.

EBR Encyclopedia of the Bible and its Reception, HELMER, C. [ET. AL.] (eds.), Berlin - New York $2009 \mathrm{ff}$.

EJ Encyclopedia Judaica, Berenbaum, M./SKolnik, F. (eds.), 22 Bde., Detroit $2007^{2}$.

FC Fontes Christiani, Turnhout 2002-2011; Freiburg im Breisgau 1990-2003; $2011 \mathrm{ff}$.

GCS Die Griechischen Christlichen Schriftsteller, Leipzig - Berlin $1897 \mathrm{ff}$.

HWPh Historisches Wörterbuch der Philosophie, RITTER, J. [ET AL.] (Hg.), Basel 1971-2007.

HWRh Historisches Wörterbuch der Rhetorik, UEDING, G. (Hg.), 12 Bde. (inkl. Nachträge, Register, Bibliographie), Tübingen - Berlin - New York 1992-2015.

LS The Hellenistic Philosophers, Long, A.A./Sedley, D.N. (eds.), 2 Bde., Cambridge 1987. Deutsche Übersetzung des ersten Bandes: Die hellenistischen Philosophen. Texte und Kommentare, übers. von K. HüLSNER, Stuttgart - Weimar 2006.

MPG Patrologiae Cursus Completus, Series Graeca, Migne, J.-P. (éd.) 161 Bde., Paris $1857-$ 1866.

MPL Patrologiae Cursus Completus, Series Latina, MIgne, J.-P. (éd.), 221 Bde., Paris 1841 1865.

RAC Reallexikon für Antike und Christentum, Stuttgart $1950 \mathrm{ff}$.

SC Sources chrétiennes, Paris $1941 \mathrm{ff}$.

SVF Stoicorum Veterum Fragmenta, H. von ARNIM (Hg.), 3 Bde., Leipzig 1903-1905 [4. Bd.: Indices, AdLER, M. (Hg.), 1924].

TRE Theologische Realenzyklopädie, 36 Bde., Berlin - New York 1976-2004.

Autorspezifische Abkürzungen sind im Literaturverzeichnis erläutert. Dort wird auch auf die verwendeten Übersetzungen von antiken Quellen ins Deutsche hingewiesen. Falls eine Passage vom Autor der vorliegenden Arbeit eigenmächtig übersetzt wurde, ist dies mit einem entsprechenden Hinweis in eckigen Klammern am Ende der jeweiligen Fußnote vermerkt. 
